мухлати аз панч то понздах соли баъди чаррохии аввалй барои ноил гардидан ба натичаи нисбатан қобили қабули эстетикй кӯчат кардани малофаи ғайриозоди соид ба кор бурда шуд.

Хулоса. Хамин тавр, дар алоқамандй аз афзалияти ин ё он компоненти иллатнокшуда риояи мархиланокии чаррохй ба таври инфиродй хал шуда ва зимнан принсипхои реконструксияи сохтори мухимми анатомй қатъиян риоя карда мешавад.

Калимахои калидй: оқибатхои сӯхтагй, дастаи рагу асабхо, малофаи соиду қадкашак, контрактураи панчаву ангуштон.

\title{
М.Э. Музафарова
}

\section{ОСОБЕННОСТИ ЛЕЧЕНИЯ И ПРОФИЛАКТИКИ БОЛЬНЫХ САХАРНЫМ ДИАБЕТОМ 2 ТИПА С ОСТЕОПОРОТИЧЕСКИМИ НАРУШЕНИЯМИ В РЕГИОНЕ С ВЫСОКОЙ РОЖДАЕМОСТЬЮ}

Кафедра эндокринологии, Таджикский государственный медициский университет им. Абуали ибни Сино

Музафарова Мехринигор Эмомхусайновна - докторант PhD кафедры эндокринологии, Таджикский государственный медицинский университет им. Абуали ибни Сино; Тел.: +(992)777004646, E-mail: mekhrinigorm@bk.ru

Цель исследования. Ознакомить с опытом ведения больных сахарным диабетом 2 типа, осложненных остеопоротическими изменениями в регионе с высокой рождаемостью.

Материаль и методы исследования. Нами наблюдались 110 больных сахарным диабетом 2 типа - 55 женщин с нормальным паритетом, 55 женщин с высоким паритетом в анамнезе. Контрольную группу составили 55 женщин аналогичного возраста не страдающие сахарным диабетом 2 типа. Исследовались показатели липидного, фосфорно-кальциевого обмена, витамин Д и маркеры костного ремоделирования. Для оценки возможной потери костной ткани применялся метод двухэнергетической рентгеновской абсорбциометрии с использованием остеоденситометра.

Результаты исследования и их обсуждение. Выбор тактики лечения больных сахарным диабетом 2 типа обосновывался исходным уровнем гликолизированного гемоглобина (HbAlc) и ведущей клинической симптоматикой. При уровне гликолизированного гемоглобина более 7\% назначалась монотерапия метформином. При исходно высоких уровнях НbAlс (8-9\%) назначалась комбинация сахароснижающчих препаратов (глипизид в сочетании с метформином; ингибитор ДПП-4 (аллоглиптин) с метформином). В группе больных с исходнылм уровнем НbА1с равному 9-9,5\% проведена терапия с ГПП-1 (лираглутид). В течении последнего года нами апробирован новый сахароснижающий препарат из группы НГЛТ-2 (дапаглифлозин), механизм которого основан на снижение реабсорбции глюкозы в почках. Отмечено устойчивое сохранение сниженного НbАІс на фоне сочетанного применения с метформином.

Использованны следующие остеопоротические препараты: золендроновая кислота (Акласта), деносумаб, терипаратид.

Заключение. Получен положительный результат индивидуального подхода к лечению больных сахарным диабетом 2 типа, осложненных остеопоротическими нарушениями путем комбинированного применения сахароснижающих препаратов и остеотропными средствами. Профилактика остеопоротических изменений постменопаузального периода у больных сахарным диабетом 2 типа должна быть комплексной с учетом поддержания уровня гликемии, борьбу с осложнениями сахарного диабета, включением регулярных дозированных физических упражнений и дополнительных мер с учетом фактора многорождаемости.

Ключевые слова: сахарный диабет 2 типа, постменопаузальный период, остеопоротические изменения, многорождаемость.

M.E. Muzafarova 
${ }^{1}$ Department of Endocrinology, Avicenna Tajik State Medical University, Dushanbe, Republic of Tajikistan

Muzafarova Mekhrinigor Emomkhusaynovna - Ph.D. candidate, Department of Endocrinology, Avicenna Tajik State Medical University; Tel.: 777004646,e-mail: mekhrinigorm@,bk.ru

Aim. To review the experience of managing patients with type 2 diabetes mellitus complicated by osteoporotic changes in a region with a high birth rate.

Materials and methods. We observed 110 patients with type 2 diabetes - 55 women with a normal parity, 55 women with a high parity in history. The control group consisted of 55 women of the same age who did not suffer from type 2 diabetes. The parameters of lipid, phosphorus-calcium metabolism, vitamin D, and markers of bone remodeling were studied. The method of dual-energy X-ray absorptiometry with an osteodensitometer was used to assess the possible loss of bone tissue.

Results. The choice of treatment tactics for patients with type 2 diabetes was based on the baseline level of glycated hemoglobin (HbAlc) and main clinical symptoms. When the level of glycated hemoglobin was more than 7\% (7.5-8.0), metformin monotherapy was prescribed. At initially high levels of HbAlc (8-9\%), a combination of antihyperglycemic drugs was prescribed (glipizide in combination with metformin; DPP-4-alogliptin inhibitor with metformin). In the group of patients with baseline HbAlc levels (9-9.5\%), therapy with GLP-1 (liraglutide) was carried out. Over the past year, a new antihyperglycemic drug from the group and NGLT-2 (dapagliflozin) was tested. Its mechanism is based on a decrease in the reabsorption of glucose in kidneys. Stable preservation of the reduced HbAlc was noted against the background of combined use with metformin. Following osteoporotic drugs were used: Zolendronic acid (Aklasta), denosumab, teriparatide.

Conclusion. An individual treatment approach to patients with type 2 diabetes complicated by osteoporotic disorders through the combined use of hypoglycemic and osteotropic medicines gave a positive result. Prevention of osteoporotic changes in patients with type 2 diabetes of the postmenopausal period should be comprehensive, taking into account the maintenance of the glycemic level under the control of the HbAlc content $\leq 7 \%$, the fight against complications of diabetes mellitus, the inclusion of regular dosed physical exercises and additional measures taking into account the multiple births factor.

Keywords: type 2 diabetes, postmenopausal period, osteoporotic changes, multiparity.

Актуальность. Известно, что число больных сахарным диабетом (СД) прогрессивно увеличивается [1]. По прогнозам Международной диабетической федерации к 2045 г. число больных СД достигнет 700 млн. человек [4]. Примечательно, что особенно драматическая ситуация создается с когортой больных СД 2 типа. Предполагается, что количество больных СД 2 типа в течении последующих 20 лет удвоится, что связано со старением населения, увеличением числа людей с ожирением и ростом этнических групп высокого риска развития диабета в мире [5]. Аналогичная ситуация с неуклонным ростом числа больных СД 2 типа складывается и в Таджикистане [2]. Сложность прогноза остеопоротических изменений у больных СД 2 типа в регионе с высокой рождаемостью обосновывает поиски новых средств, направленных на комплексную терапию данного недуга, а также разработку специфических мер профилактики.

Цель исследования. Ознакомить с опытом ведения больных сахарным диабетом 2 типа, осложненных остеопоротическими изменениями в регионе с высокой рождаемостью.

Материалы и методы исследования. Нами наблюдались 110 больных СД 2 типа, из них 55 женщин с нормальным паритетом и 55 женщин с высоким паритетом в анамнезе. Средний возраст обследованных составил 58,8 лет. Контрольную группу составили 55 женщин аналогичного возраста не страдающих СД 2 типа. Критериями включения были: пациентки с СД 2 типа в постменопаузальном периоде в состоянии различной степени компенсации диабета; возраст 45-65 лет; длительность диабета от 5 лет. Критериями исключения являлись: больные СД 1 типа; терминальные стадии нефропатии; ревматические заболевания; прием глюкокортикоидов в анамнезе; наличие других эндокринных заболеваний.

Нормальная масса тела была у 26 женщин, избыточная - у 48, а ожирение - у 36 . Во всех случаях у женщин был менопаузальный период. Среди исследуемых, у 80 женщин была диагностирована артериальная гипертензия, у 30 ишемическая болезнь сердца.

Всем больным проводились клинико-лабораторные исследования крови и мочи биохимические анализы (показатели гликемии, содержание гликолизированного гемоглобина; общего холестерина; ХС-ЛПВП; показатели фосфорно-кальциевого обмена; витамин Д; маркеры костного ремоделирова- 
ния). Из инструментальных методов исследования для оценки возможной потери костной ткани применялся метод двухэнергетической рентгеновской абсорбциометрии с использованием остеоденситометра Hologic Discovery Wi (S/N 88426, USA). Исследования выполнялись в трех стандартных участках опорно-двигательного аппарата: поясничном отделе позвоночника, проксимальной части бедренной кости, дистальных отделах костей предплечья. Статистический анализ проведен на персональном компьютере с помощью программы «Statistica 10,0».

Результаты исследования и их обсуждение. В динамике ведения всех больных сахарным диабетом 2 типа мы придерживались основного условия - это коррекция гликемии. Для выполнения этой задачи проводилась работа, направленная на модификацию образа жизни и подбор адекватной медикаментозной терапии. Выбор тактики лечения больных СД 2 типа обосновывался исходным уровнем гликолизированного гемоглобина (HbA1c) и ведущей клинической симптоматикой. При уровне гликолизированного гемоглобина более 7\% $(7,5-8,0)$ назначалась монотерапия метформином, при отсутствии противопоказаний (наличие гипоксических состояний). Применение метформина способствовало снижению уровня HbA1с на 1-2\%, характеризовалось отсутствием прибавки веса и низким риском гипогликемии. В группе больных СД 2 типа в состоянии субкомпенсации и декомпенсации при исходно высоких уровнях НbA1c (8-9\%) назначалась комбинация сахароснижающих препаратов (глипизид в сочетании с метформином; высокоселективный ингибитор ДПП-4 (аллоглиптин) с метформином). Назначение последней комбинации позволило у более чем 50\% пациентов с СД 2 типа достигнуть уровня НbA1c до 7\%. Терапия ГПП-1 (лираглутид), проведенная в группе больных с исходным уровнем НbA1с равным 9-9,5\% способствовало более выраженному по сравнению с ДПП-4 снижению HbA1c (на 0,8-1,8\%), ассоциировалась с низким риском гипогликемии, снижением массы тела и уровня артериального давления. Следует отметить, что у 4 пациентов в начале лечения препаратом отмечались диспептические проявления. В течении последнего года нами апробирован новый сахароснижающий препарат из группы и НГЛТ-2 (дапаглифлозин), механизм которого основан на снижение реабсорбции глюкозы в почках. Сахароснижающий эффект у НГЛТ-2 по степени снижения $\mathrm{HbA1}$ с составил примерно 0,8\%. Отмечено устойчивое сохранение сниженного HbA1c на фоне сочетанного применения с метформином.

Следовательно, терапия больных СД 2 типа в регионе с высокой рождаемостью определялась как ведущей клинической проблемой (наличием ожирения, сердечно-сосудистых заболеваний), так и степенью снижения уровня $\mathrm{HbA1c}$, риском возникновения гипогликемий и возможными побочными явлениями. Существенной разницы в изменениях со стороны костной системы в зависимости от вида получаемой сахароснижающей терапии не выявлено.

Контингенту больных сахарным диабетом 2 типа с остеопоротическими изменениями наряду с основной терапией сахарного диабета дополнительно назначалось лечение остеотропными средствами. С учетом патогенетических свойств препаратов, приверженности и финансовых возможностей пациентов использовались следующие препараты: золендроновая кислота (Акласта) назначена 5 пациентам, деносумаб - 15 пациентов, терипаратид - 2 пациента. С учетом полученных результатов обследования больных в схему комплексной терапии были включены также витамин Д и препараты кальция.

Среди примененных препаратов для лечения остеопороза у пациентов с СД 2 типа следует особо выделить препарат деносумаб. Это первый антирезорбтивный препарат, действие которого основано на регулировании системы костного ремоделирования RANK-L-RANK-OPG. Важным преимуществом препарата является отсутствие влияния на почечную функцию. Деносумаб представляет собой раствор для подкожного введения 1 мл, содержащий 60 мг активного вещества вводимый 1 раз в 6 месяцев.

Следует отметить, что у 2 пациентов в процессе применения препарата наблюдались гипокальциемия и в 2 случаях боль в конечностях, которые в динамике самопроизвольно устранились.

В динамике применения препарата отмечен достоверный прирост минеральной плотности костной ткани, особенно в области позвоночника, а также уменьшение в сыворотке крови концентрации маркера резорбции костной ткани - C телопептида (СТХ), тенденция к увеличению содержания остеокальцина в крови.

Таким образом, использованный принцип индивидуализации лечения больных СД 2 типа с остеопоротическими нарушениями позволил получить положительный эффект. Нами получен положительный результат применения указанной 
терапии у 22 больных СД 2 типа с остеопоротическими нарушениями в процессе 2-х лет наблюдения. Исследования продолжаются.

Приведенные данные согласуются с результатами исследований ряда авторов, посвященных вопросам лечения больных СД 2 типа и проблемами остеопороза [3-8] и дополняются новыми сведениями с учетом выявленных регионарных особенностей.

Тщательный анализ факторов риска возникновения остеопоротических нарушений позволили отметить гипергликемию, как наиболее важный фактор риска. Наряду с гипергликемией и поздними осложнениями сахарного диабета факторами риска костных поражений у больных с СД 2 типа в регионе высокой рождаемости являются паритет и низкий интергенетический интервал.

Выводы. Получен положительный результат индивидуального подхода к лечению больных СД 2 типа, осложненных остеопоротическими нарушениями путем комбинированного применения сахароснижающих препаратов под контролем содержания гликолизированного гемоглобина в крови и остеотропными препаратами дифференцированно с использованием их патогенетических свойств в регионе с высокой рождаемостью.

Профилактика остеопоротических изменений у больных СД 2 типа постменопаузального периода должна быть комплексной с учетом поддержания уровня гликемии (уровень гликолизированного гемоглобина $\leq 7 \%$ ), борьбу с осложнениями сахарного диабета, включением регулярных дозированных физических упражнений и дополнительных мер с учетом фактора многорождаемости.

\section{ЛИТЕРАТУРА \\ (III. 8-10 cM. B REFERENCES)}

1. Алгоритмы специализированной медицинской помощи больным сахарным диабетом. Под ред. И.И. Дедова, М.В. Шестаковой (8-й выпуск). Сахарный диабет, 2017, 20(15): 1-112.

2. Анварова Ш.С. Распространение сахарного диабета 2 типа в коморбидности с основным фактором метаболического синдрома в Таджикистане. Материалы конгресса кардиологов и терапевтов стран Азии и СНГ. «Актуальные проблемы сердечно-сосудистых и соматических заболеваний». Душанбе 2019 стр. 100-101.

3. Белая Ж.Е., Рожинская Л.Я. Новые направления в терапии остеопороза-применение моноклональных человеческих антител к RANKL (деносумаб) // Ж. Остеопороз и Остеопатии, 2011, №2, с.19-22.

4. Глобальный доклад по диабету [Global report on diabetes]. Женева: Всемирная организация здравоохра- нения; 2018. Лицензия: CC BY-NC-SA 3.0 IGO.

5. Пирматова Д.А. Особенности течения беременности и родов у женщин с гестационным сахарным диабетом / Д.А. Пирматова, М.Ф. Додхоева, К.Г. Пархофер // Вестник Академии медицинских наук Таджикистана. 2020. T. 10. № 2 (34). C. 163-167.

6. Тагоев Т.С. Заболеваемость сахарным диабетом детей и подростков как медико-социальная проблема в Республике Таджикистан. / Т.С. Тагоев, Ф.Т. Каюмов, И.С. Бандаев, И.А. Хакназаров // Вестник последипломного образования в сфере здравоохранения. 2020. № 3. C. 79-84.

7. Шарофова М.У. Сахарный диабет: современное состояние вопроса (часть 2) / М.У. Шарофова, Ш.С. Сагдиева, С.Д. Юсуфи // Вестник Авиценны. 2019;21(4):661-74.

\section{REFERENCES}

1. Algoritmy spetsializirovannoy meditsinskoy pomoshchi bolnym sakharnym diabetom. Pod red. I.I. Dedova, M.V. Shestakovoy (8-y vypusk) [Algorithms of specialized medical care for patients with diabetes mellitus. Edited by I.I. Dedov, M.V. Shestakova (8th issue)]. Sakharnyy diabet - Diabetes, 2017, No. 20 (15), pp. 1-112.

2. Anvarova Sh.S. [Prevalence of Type 2 Diabetes Mellitus in Comorbidity with Major Metabolic Syndrome Factor in Tajikistan]. Materialy kongressa kardiologov $i$ terapevtov stran Azii i SNG. «Aktualnye problemy serdechno-sosudistykh i somaticheskikh zabolevaniy" [Materials of the Congress of Cardiologists and Therapists of Asia and CIS countries. «Topical problems of cardiovascular and somatic diseases»]. Dushanbe, 2019, pp. 100-101. (In Russ.)

3. Belaya Zh.E., Rozhinskaya L.Ya. Novye napravleniya $\mathrm{v}$ terapii osteoporoza-primenenie monoklonalnykh chelovecheskikh antitel k RANKL (denosumab) [New directions in osteoporosis therapy-use of monoclonal human antibodies to RANKL (denosumab)]. Zhurnal «Osteoporoz i Osteopatii» - Osteoporosis and Osteopathy Journal, 2011, No. 2, pp. 19-22.

4. Vsemirnaya organizatsiya zdravookhraneniya Globalnyy doklad po diabetu [Global report on diabetes]. Zheneva, 2018.

5. Pirmatova D.A. Osobennosti techeniya beremennosti i rodov u zhenshchin s gestatsionnym sakharnym diabetom [Peculiarities of pregnancy and childbirth in women with gestational diabetes mellitus]. Vestnik Akademii meditsinskikh nauk Tadzhikistana - Bulletin of the Academy of Medical Sciences of Tajikistan, 2020, Vol. 10, No. 2 (34), pp. 163-167.

6. Tagoev T.S. Zabolevaemost sakharnym diabetom detey i podrostkov kak mediko-sotsialnaya problema $\mathrm{v}$ Respublike Tadzhikistan [The incidence of diabetes in children and adolescents as a medical and social problem in the Republic of Tajikistan]. Vestnik poslediplomnogo obrazovaniya $v$ sfere zdravookhraneniya - Herald of postgraduate education in healthcare sphere, 2020, No. 3, pp. 79-84.

7. Sharofova M.U. Sakharnyy diabet: sovremennoe 
sostoyanie voprosa (chast 2) [Diabetes mellitus: state of the art (part 2)]. Vestnik Avitsenny - Avicenna Bulletin, 2019, No. 21 (4), pp. 661-674.

8. Martin-Penabver J.J., Martin-Timon., Sellivano-Collantes C., Del Canizo-Gomez F.J. Update on the treatment of type 2 diabetes mellitus. World Journal of Diabetes, 2016, No. 15,7 (17), pp. 354-395.

9. Seck T., Nauck M., Sheng D. et al Safety and efficacy of treatment with sitagliptin of glipizide in patients with type 2 diabetes inadeguately controlled of metformin: a 2-year study International Journal of Clinical Practice, 2010, No. 64 (5), pp. 562-576.

10. Nauck M.A., Del Prato S, Duran-Garcia S. et al Durability of glicaemic efficacy over 2 years with dapagliflozin versus glipizide as add-on Hrerapies in patients whose type 2 diabetes mellitus is inaduguately controlled with metformin. Diabetes, Obesity and Metabolism, 2014, No. 16 (11), pp. 1111-1120.

\section{ХУЛОСА}

М.Э. Музафарова

\section{ХУСУСИЯТХОИ ТАБОБАТ ВА ПЕШГИРИИ БЕМОРОНИ ДИАБЕТИ НАВЫИ 2, БО ИХ- ТИЛОТИ ОСТЕОПОРОТИКИ ДАР МИНТА- КАИ ХОСИЛНОКИИ БАЛАНД}

Мақсади тадқиқот. Шинос шудан бо тачрибаи идоракунии беморони гирифтори диабети навъи 2, ки бо оризаи остеопорозй дар минтақаи таваллуди баланд гирифтор шуданд.

Маводхо ва усулхои тадқиқот. Мо 110 беморони гирифтори диабети навъи 2 - 55 зан бо паритети муқаррарй, 55 зани дорои паритети баланд, ки дар анамнез доштанд мушохида кардем. Гурӯхи назоратй аз 55 зани хамонсола иборат буд, ки аз диабети навъи 2 азият намекашиданд. Параметрхои мубодилаи липидхо, фосфор-калсий, витамини D ва маркерхои азнавсозии устухонхо омӯхта шуданд. Барои арзёбии талафоти эхтимолии бофтаи устухон усули абсорбтиометрияи рентгении дуэнергетикй бо истифода аз остеденситометр истифода шуд.

Натичахои тадқиқот ва мухокимаи онхо. Интихоби усули табобат барои беморони гирифтори диабети навъи 2 бо сатхи ибтидоии гемоглобини гликатсияшуда (HbA1c) ва нишонахои пешбари клиникй тасдиқ карда шуд. Вақте ки сатхи гемоглобини гликатсияшуда зиёда аз 7\% $(7,5-8,0)$ буд, монотерапияи метформин таъин карда мешавад. Дар аввал дар сатхи баланди HbA1c (8-9\%) мачмууи дорухои зидди гипергликемикй таъин карда шуд (глипизид дар якчоягй бо метформин; ингибитори DPP-4-аллоглиптин бо метформин). Дар гуруухи беморони дорои сатхи ибтидоии HbA1c (9-9,5\%), табобат бо GLP-1 (лираглютид) гузаронида шуд. Дар давоми як соли охир мо як доруи нави антигипергликемикии гурӯх ва NGLT-2 (дапаглифлозин)-ро озмоиш кардем, ки механизми он ба паст шудани реабсорбсияи глюкоза дар гурдахо асос ёфтааст. Нигохдории устувори камшавии HbA1c дар заминаи истифодаи якчоя бо метформин қайд карда шуд. Дорухои остеопоротики истифодашаванда: Кислотаи Золендрон (Акласта), деносумаб, терипаратид.

Хулоса. Натичаи мусбати муносибати инфиродй ба табобати беморони гирифтори диабети навъи 2 , ки бо ихтилоли остеопороз мушкил шудааст, тавассути истифодаи якчояи дорухои гипогликемикй ва дорухои остеотропй ба даст омад. Пешгирии тағйироти остеопорозй дар беморони гирифтори диабети навъи 2 дар давраи пас аз менопауза бояд хамачониба гузаронида шавад, бо назардошти нигох доштани сатхи гликемикй тахти назорати мундаричаи $\mathrm{HbAlc} \leq 7 \%$, мубориза бо мушкилихои диабети қанд, ворид кардани дорухо, мунтазам машқхои физкультурии, доза ва тадбирхои иловагй бо назардошти омили серфарзанд доимо дар зери назорат бошад.

Калимахои калиди: диабети навъи 2, давраи баъдименопаузй, тағйироти остеопорозй, бисёрчониба.

\section{ЛАПОРОСКОПИЯ В ДИАГНОСТИКЕ ПОВРЕЖДЕНИЙ ОРГАНОВ БРЮШНОЙ ПОЛОСТИ ПРИ ТУПОЙ ТРАВМЕ}

